Department Animal Diseases,

Veterinary, College- AL-Bath University, Syria.

\title{
SEROLOGY STUDY ON ENZOOTIC ABORTION OF EWES IN NORTH AREA OF SYRIA
}

(With 3 Tables)

By

\section{E. OTHMAN; Y. ALYASINO and Y. ALOMAR}

(Received at 20/11/2010)

دراسة مصلية عن مرض إجهاض الأغنام المستوطن في المنطقة الشمالية

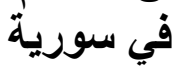

\section{عيسى العثمان ، ياسلين الياسينو ، ياسسر العمر}

أجُريت الدر اسة على 418 نعجةً مجهضةً بأعمار مختلفة في 24 قطيع أغنام في 6 مناطق ضمن محافظتين. من بين 418 عينة مصل تم جمعها من أغنام مجهضة وتم وتم اختبار ها من

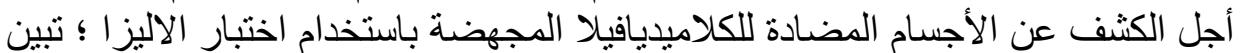

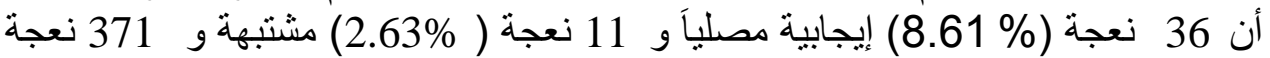

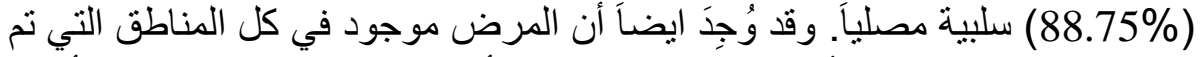

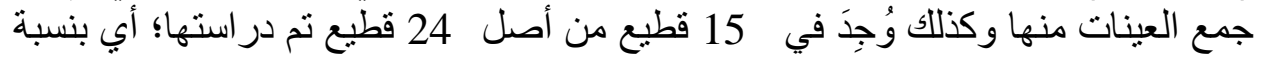

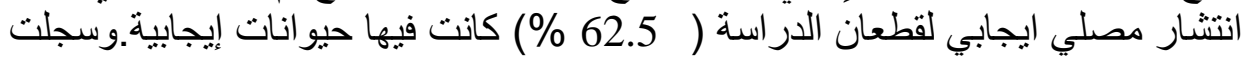

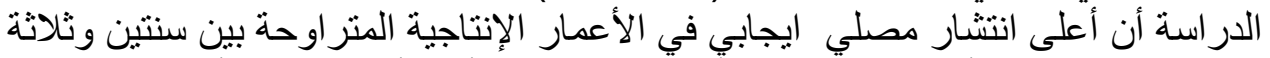

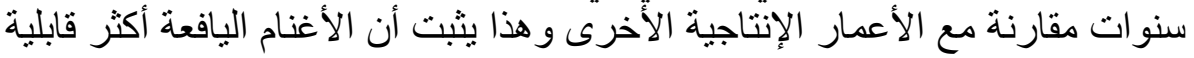
للإصابة مقارنة مع النعاج الفتية و المعدرة.

\section{SUMMARY}

The study was carried out on 418 aborted ewes in different ages in 24 sheep folds in 6 regions within two province (mohafazat) the study confirmed that positive seroprevalence in 36 aborted ewes was $(8.61 \%)$, 11ewes were suspected $(2.63 \%)$ and 371 ewes were reported negative reaction to ELISA test $(88.75 \%)$. The positive cases were reported in all study regions and the positive cases were reported in 15 fold of 24 study population as seropositive percent $(62.5 \%)$ folds level. The study reported that the higher positive seroprevalence were in productivity age range between 2 and 3 years old comparing with other ages. This confirms that adult ewes were near susceptible animals to the infection comparing with young and old ewes.

Key words: Enzootic abortion, Syria, serology. 


\section{INTRODUCTION}

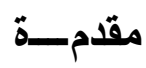

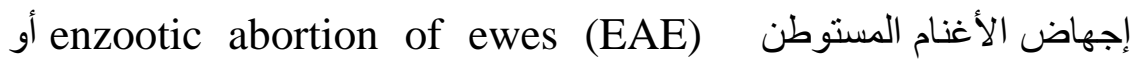

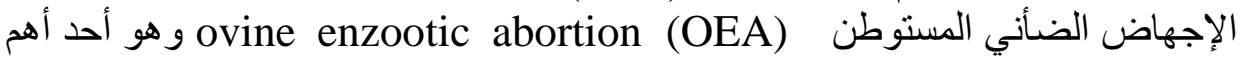

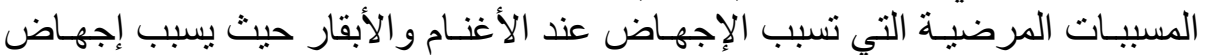
الأغنام المستوطن عند الأغنام، وإجهاض الأبراض الأقار الوبائي عند الأبقار

.(Nietfeld, 2001; Entrican, 2002

العامل المسبب لهذا المرض هو جر اثيم الكلاميديافيلا المجهضية

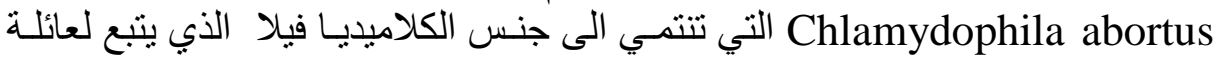

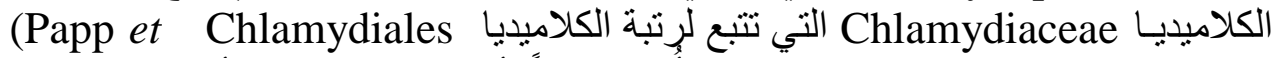
al., 1994 ; Everett et al., 1999)

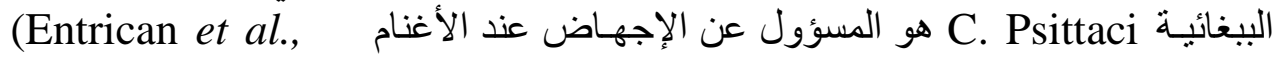

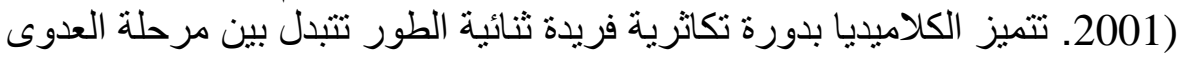

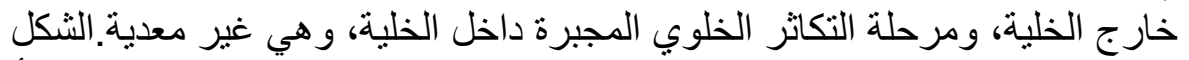

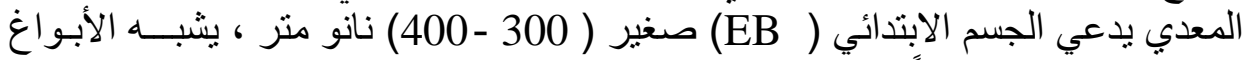

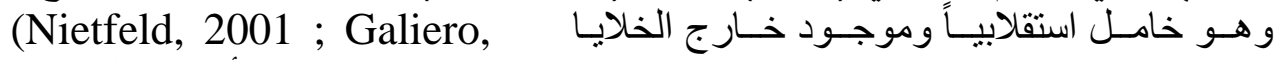

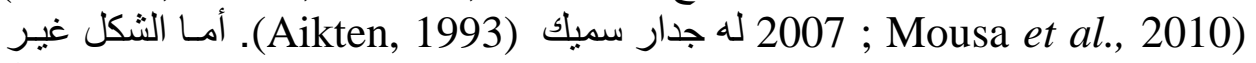

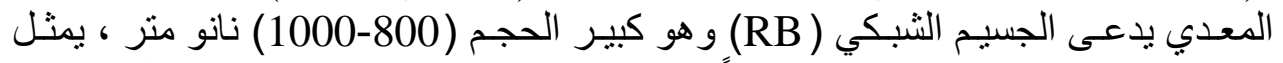

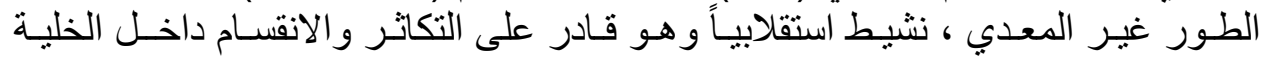
(Nietfeld, 2001 ; Galiero, 2007 ; Mousa et al., 2010)

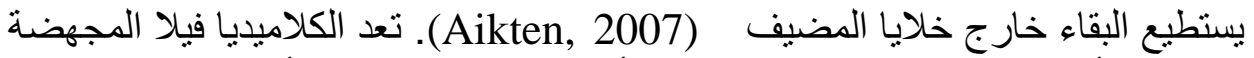

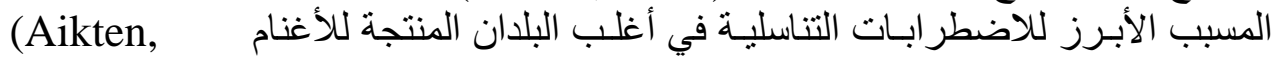

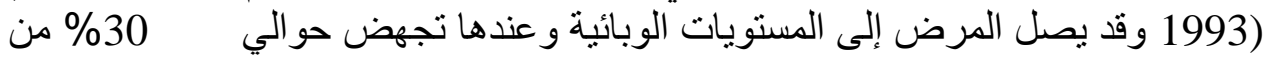

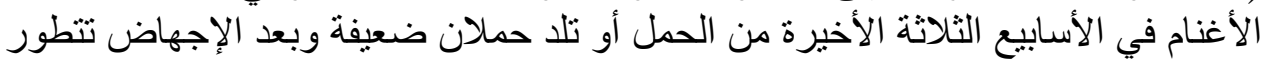

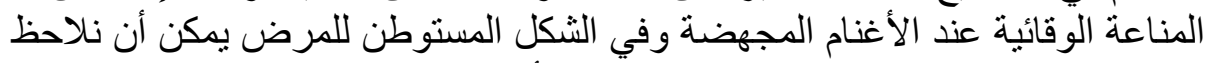

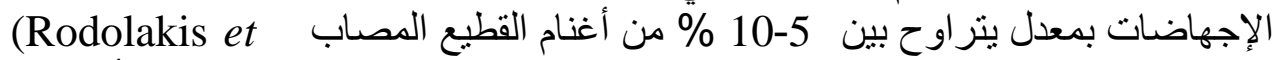

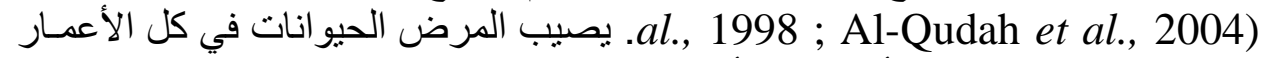

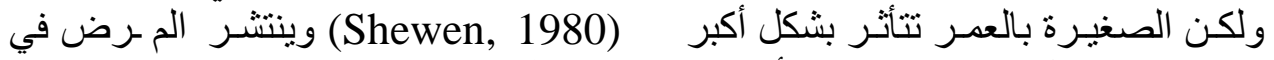

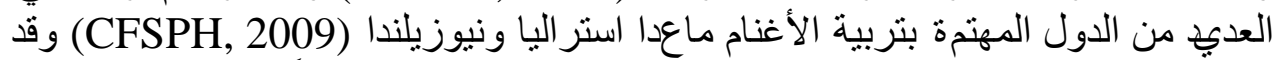

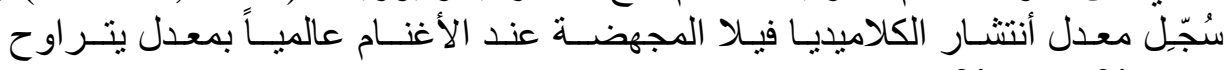

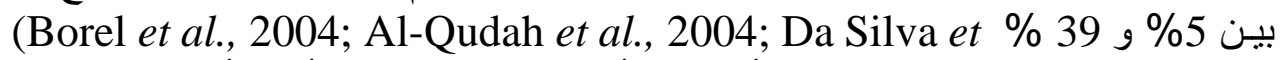

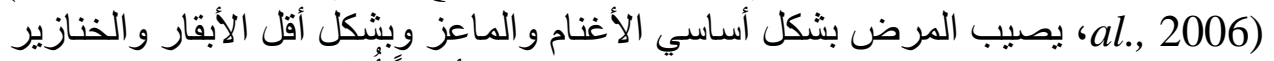

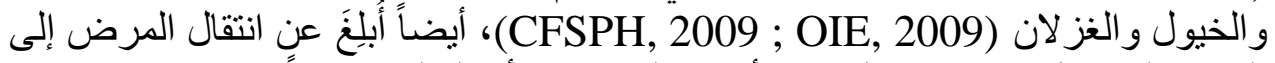

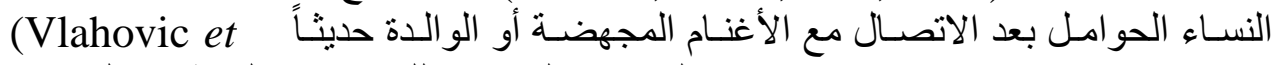

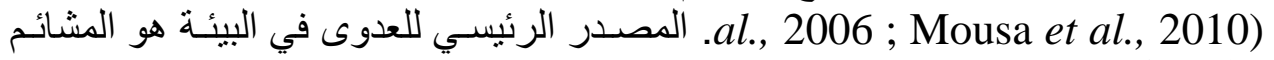
و السوائل الجنينية من الحيو انـات المصابـة (Appleyard et al., 1985) حيث تبقى ليثى 
الأجسـام الأوليـة معديـة لعدة أيام (Papp et al., 1994) ينتقل المرض عن طريق تنتاول

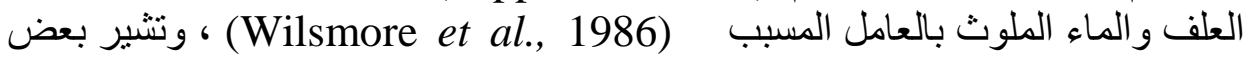
التقارير إلى انتقاله عن طريق الاستنشاق (Jones and Anderson, 1988) وبالاستنـاد

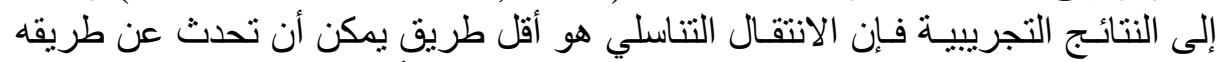

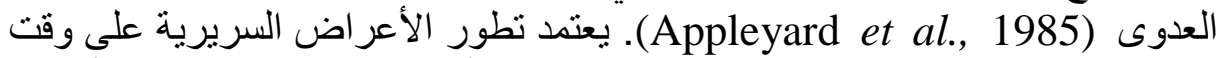

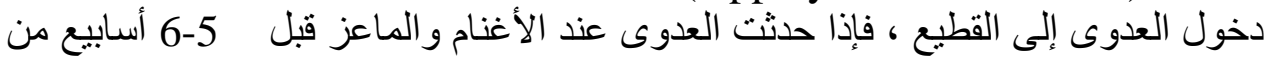

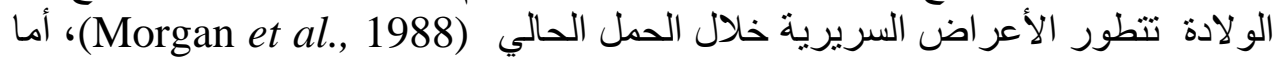

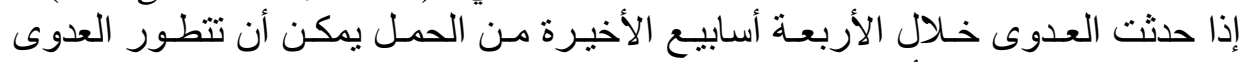

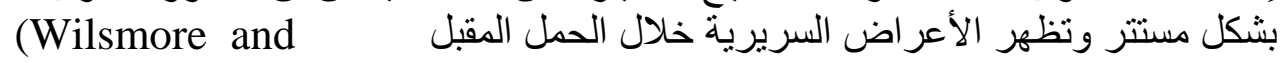
Dawson, 1990)

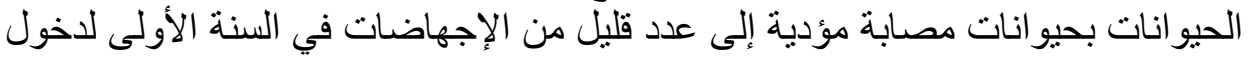

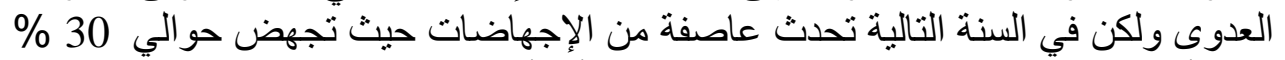

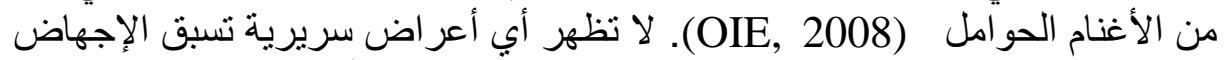
بالر غم من التغيرات السلوكية والاطلاقات المهبلية التي يمكن أن تلاحظ خلاعل 48 ساعة الإنة

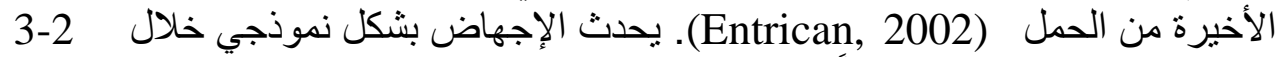

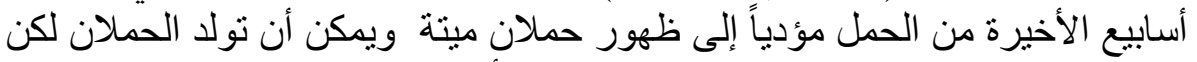
تكون ضعيفة ولا تستطيع البقاء على قيد الحيد الحياة لأكثر من

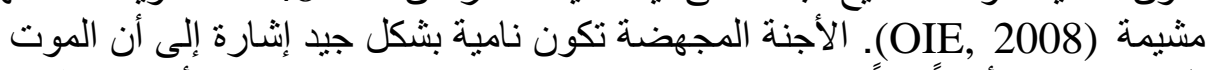

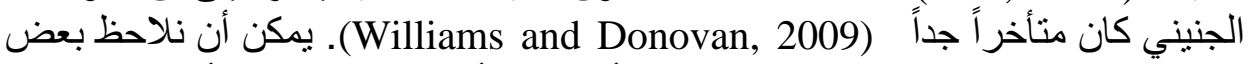

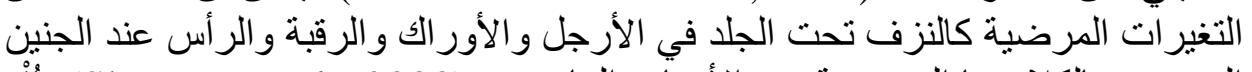

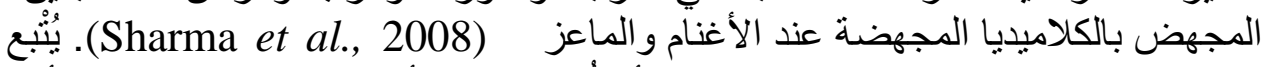
الإجهاض بطرح سوائل مهبلية وسخة يمكن أن تُلاحظ لمدة ألكثر من سبعة إلى عشرة الئل أليام

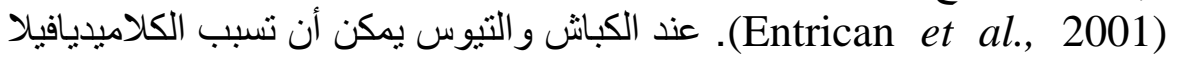

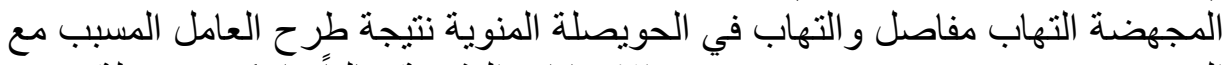

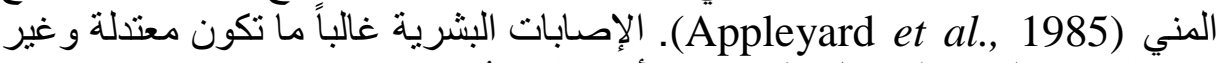

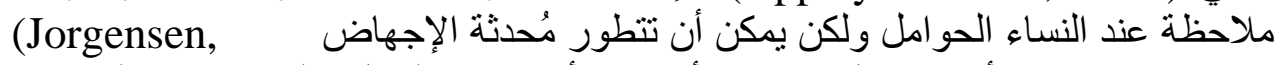

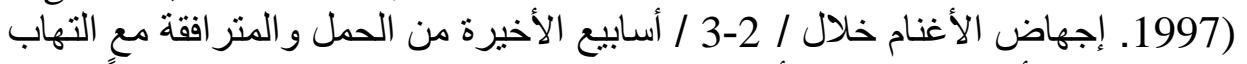

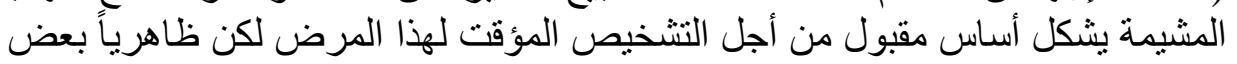

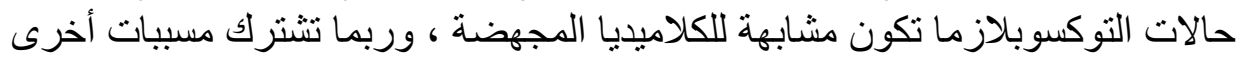

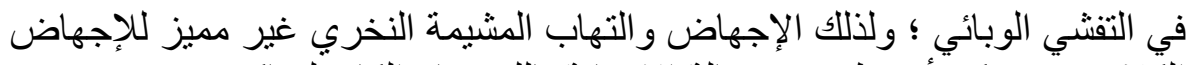

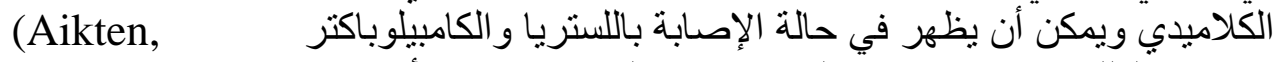

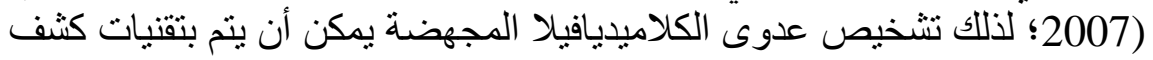
المستضد المختلفة التي تتضمن polymerase chain reaction (PCR) و الكيمياء النسيجية histochemical و الصبغات المناعية immunological staining للمسحسات

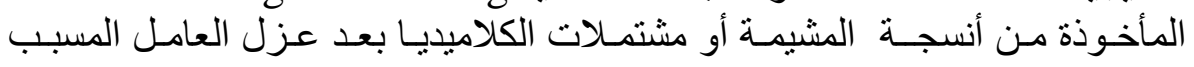

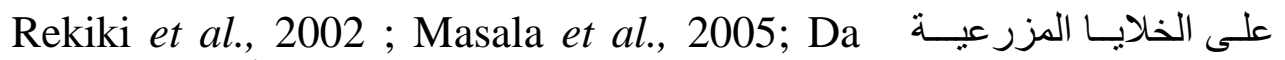
(Nietfeld, 2001 ; Silva et al., 2006) 
الاختبار ات تعتمد على المادة التشخيصية ذات النوعية الجيدة و المحفوظة بشكل جيد و على الحي الاختصاصبين ذوي الخبرة و الكفاءة العالية.

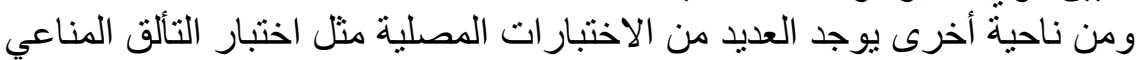
immunofluorescence tests (IFATs)

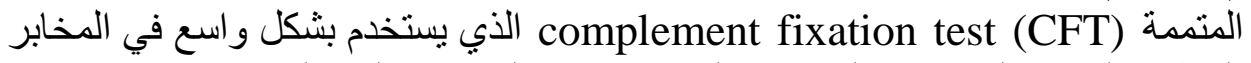
البيطرية لتحديد الحيو انات المصابة بالكلاميديا فيلا المجهضة لكن التفاعلات الانتيجينية

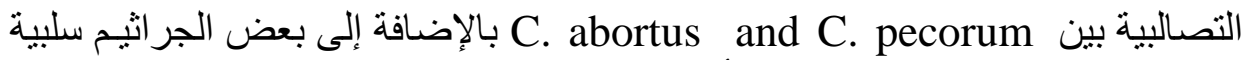
الغرام مثل Acinetobacter يمكن أن تيؤدي إلى نتائج إيجابية خاطئة في اختبار تثبيت

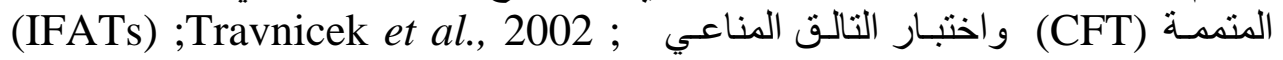
Longbottom et al., Niemczuk et al., 2005; Da Silva et al., 2006) 2002) في العام 2007 ذكر الباحث Vretou وزمـلاؤه بـان اختبـار الاليزا من أجلـ

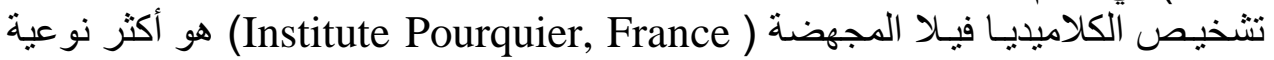
وحساسية من اختبار تثبيت المتممة من أجل التشخيص المصلي لمرض إجهاض الأغنام المستوطن (Vretou et al., 2007)

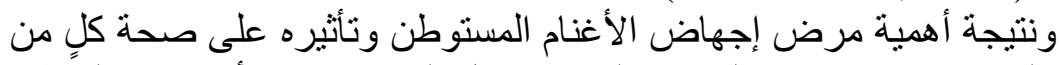

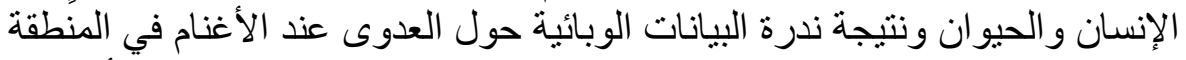

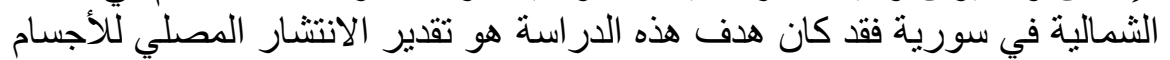

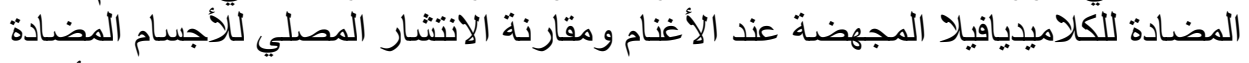

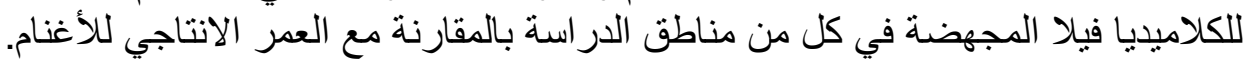

\section{MATERIALS and METHODS مواد وطرائُ البحث}

\section{مواد البحث Materials: مينات: جمع العينات: Sampling collection}

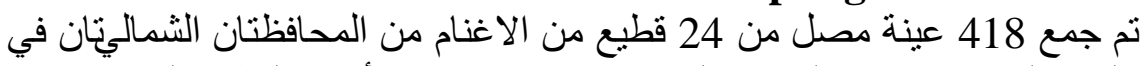

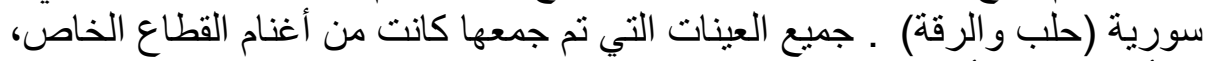

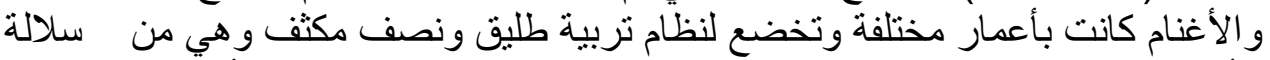

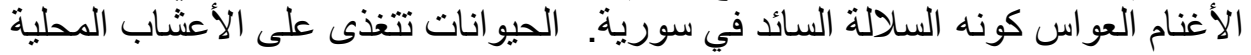

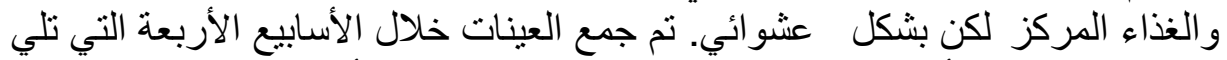

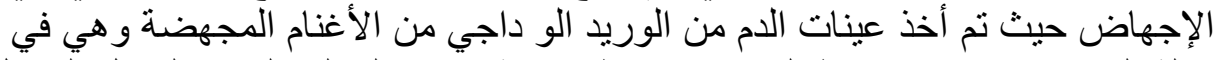

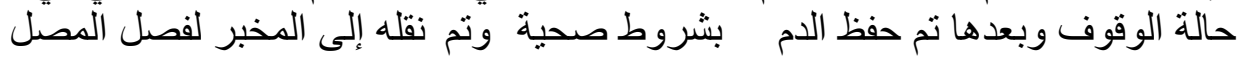

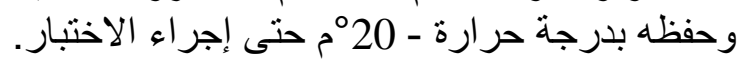
مواد العمل المخبري

استخدم مجمو عة تشخيصية لاختبار المقايسة المناعية المرتبطة بالأنظيم (ELISA) Pourquier Institute POURQUIER® ELISA CHLAMYDOPHILA. abortus serum Verification - Version P00700/06, France 


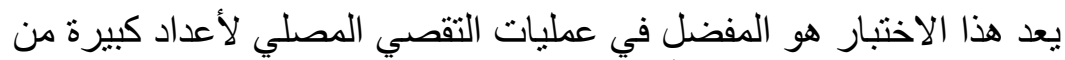

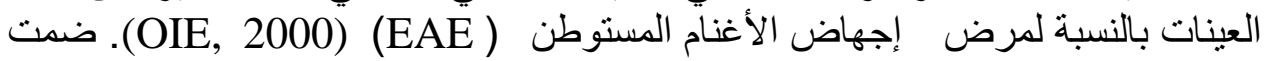
المجمو عة التشخيصية المواد التالية: 1- طبق الإليزا ILISA يحتوي على 96 حفرة ميكروليترية مرقمة من A1 وحتى H12 مغطاة بمستضد الكلاميديا فيلا المجهضي الإليز

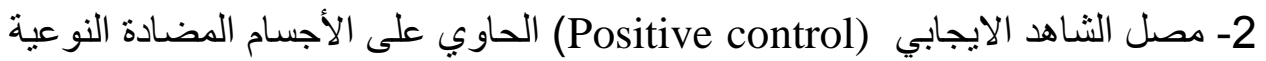
لكلاميديا فيلا المجهضة. 3- مصل الثـاهد السلبي (Negative control) الخالي تماماً من الأجسام المضادة النو عية للكلاميديا فيلا المجهضة. 4- محلول التمديد 4 (Dilution Buffer 4): يستخدم هذا المحلول من اجل تمديد أمصال

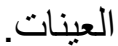
5- محلول التمديد 1 ( Dilution Buffer 1 (D) يستخدم هذا المحلول من اجل تمديد

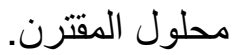

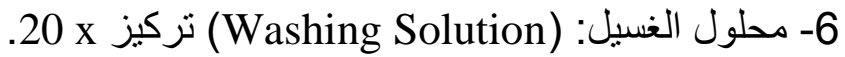

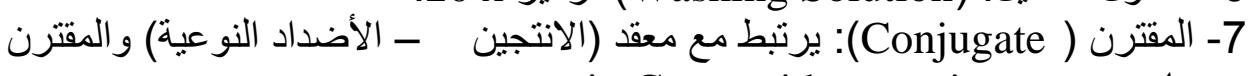

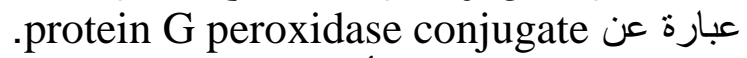

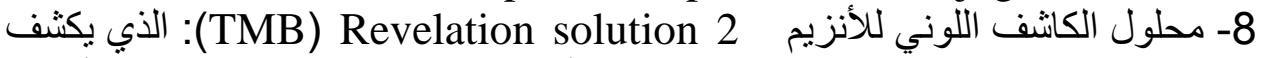
كمية الارتباط بين محلول الاقتر ان المرتبط بالأنزيم ومعقد (الانتجين الأضداد

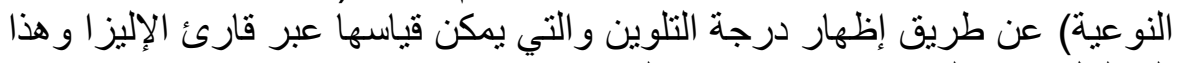

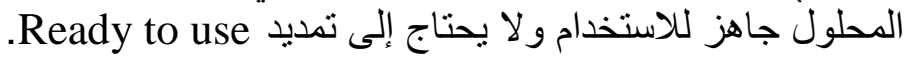

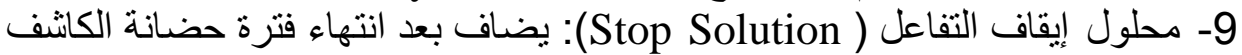
اللوني للأنزيم لإيقاف و إنهاء التفاعل الحاصل ويتألف من من محلف .(H2SO4 0,5 M solution) M

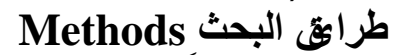

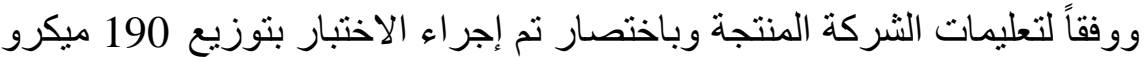

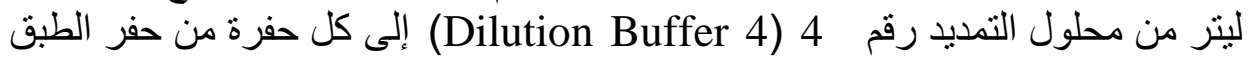

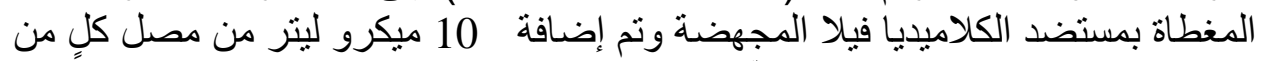

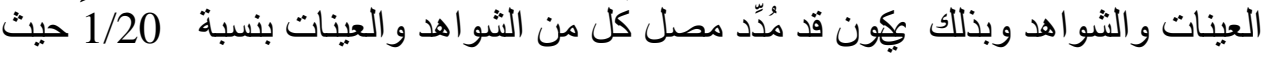

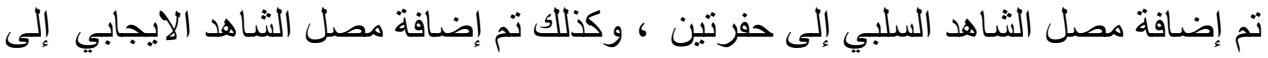
حفرتين ومصل العينات إلى باقي حفر الطبق.

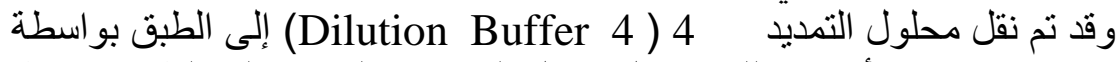

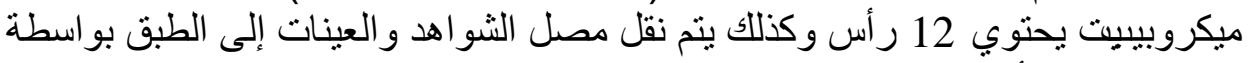

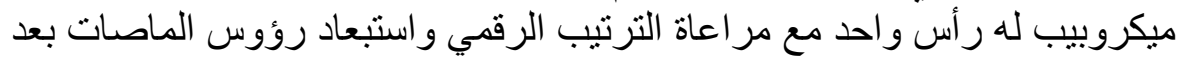

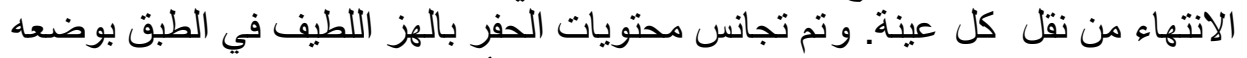

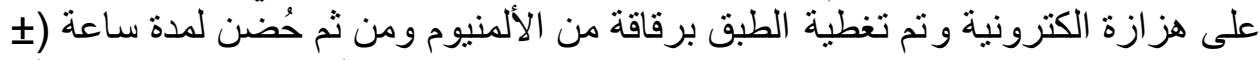

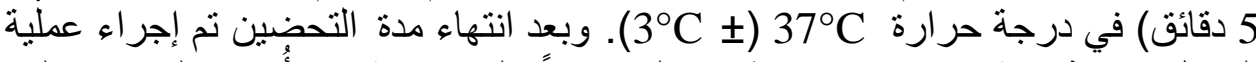

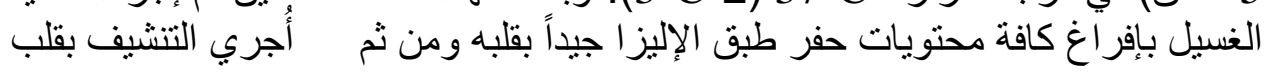


الطبق على ورق نشاف نظيف وجاف عدة مرات ومن ثم تم ملء الحفر في الطبق بمحلول

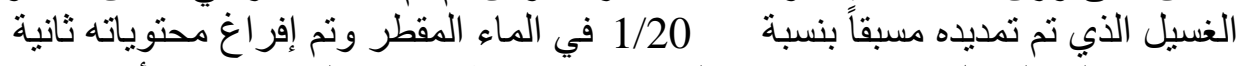

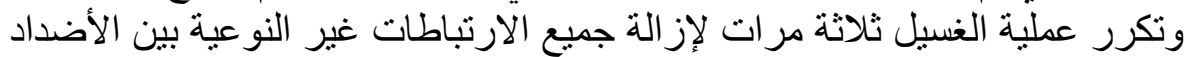

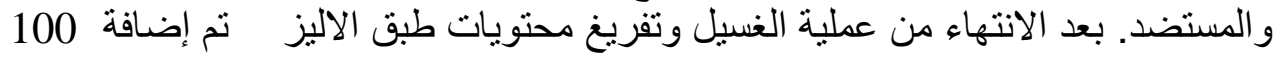

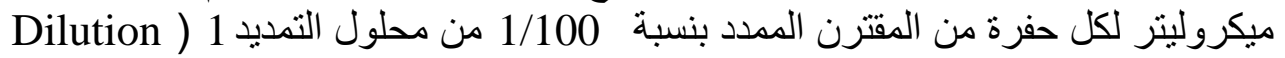
Buffer 1

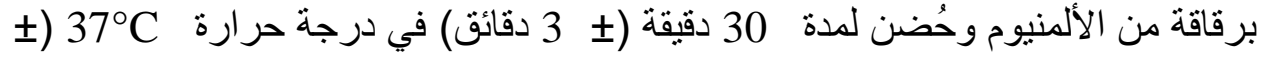
.$\left(5^{\circ} \mathrm{C}\right.$

بعد انتهاء مدة التحضين نم إجر اء عملية الغسيل مرة ثانية وتكرر عملية الغسيل

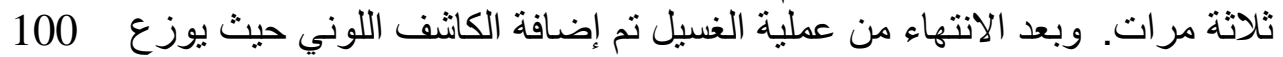

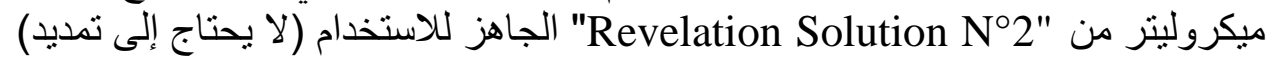

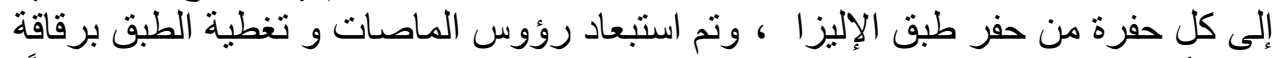

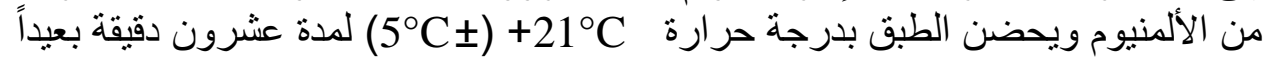

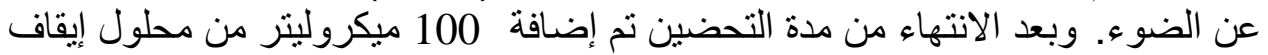

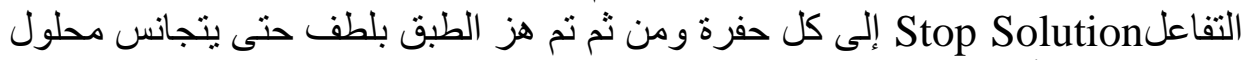

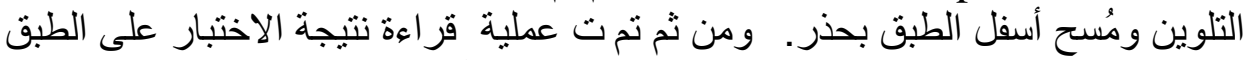

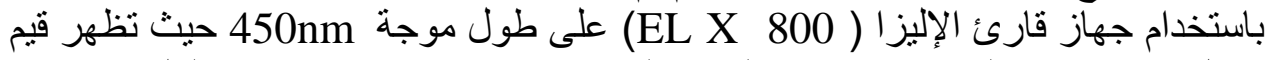

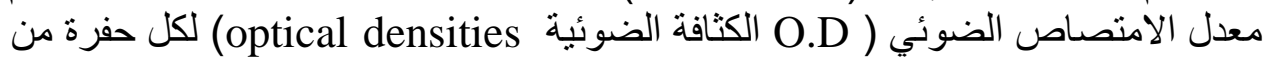

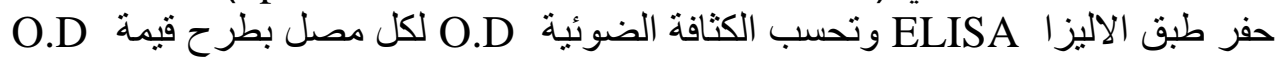

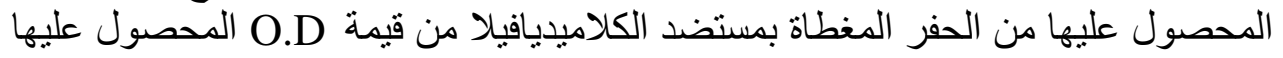

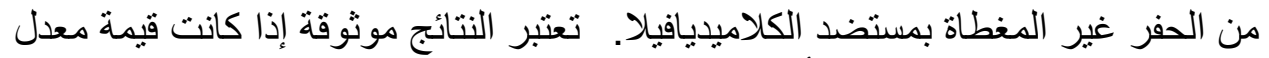

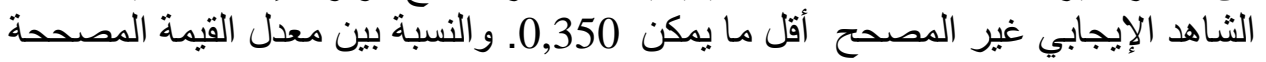

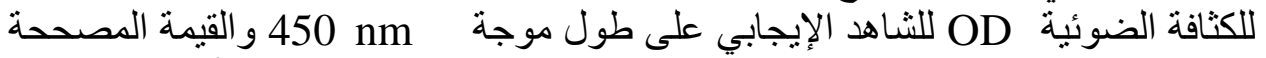
للكثافة الضوئية OD للشاهد السلبيّ على طول موجة

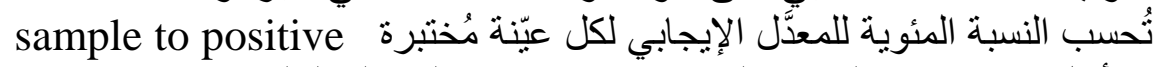

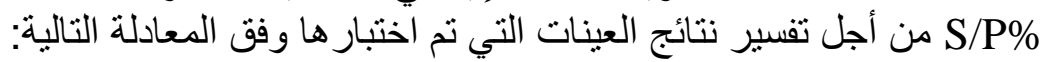
$\mathrm{S} / \mathrm{P} \%=$ (corrected OD450 of the sample/mean corrected OD450 of the positive control) $\mathrm{x} 100$

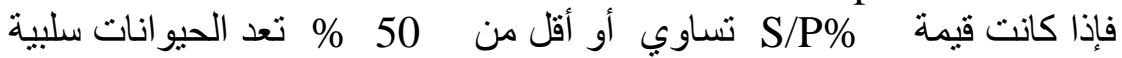

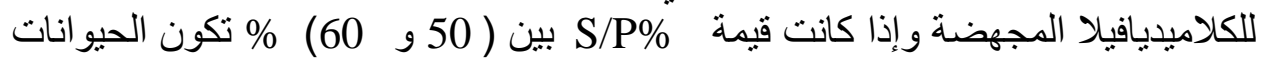

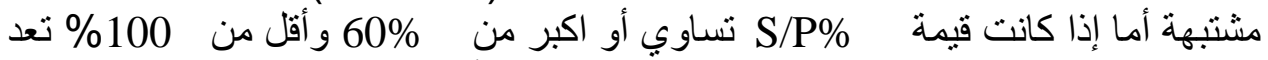

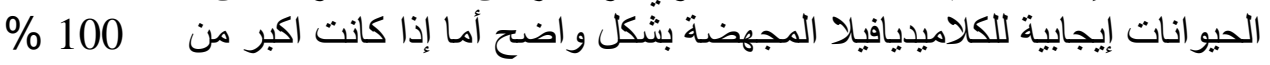
فإنها تعد إيجابية.

\section{RESULTS}

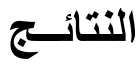


تم دراسة 24 قطيع أغنام في المنطقة الثمالية في سورية في محافظتان هما

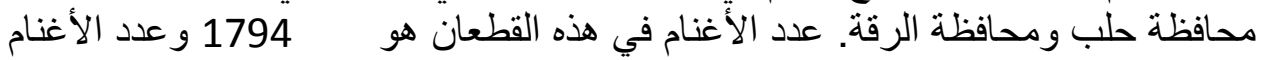

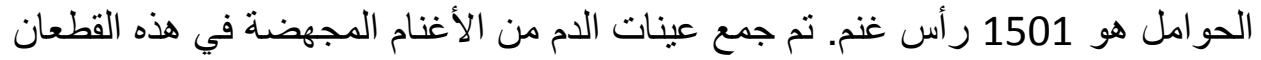

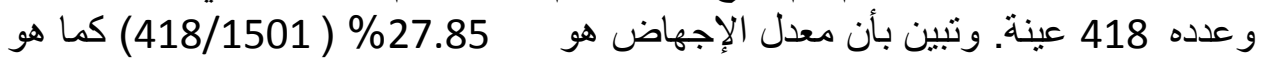
موضح في الجدول رقم (1)

الجدول رقم 1: معدل الإجهاض عند الأغنام الحوامل في المنطقة الثمالية من سورية.

\begin{tabular}{|c|c|c|c|c|}
\hline معدل الإجهاض (\%) & عدد الإناثة & عدد الإناث & القطعان & المحافظة \\
\hline $26.80(363 / 1354)$ & 363 & 1354 & 22 & حلب \\
\hline $37.41(55 / 147)$ & 55 & 147 & 2 & 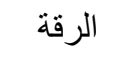 \\
\hline $27.85(418 / 1501)$ & 418 & 1501 & 24 & المجموع \\
\hline
\end{tabular}

كما وجدت الأجسام المضادة للكلاميديافيلا المجهضة في 15 قطيع من أصل 24 ألمان

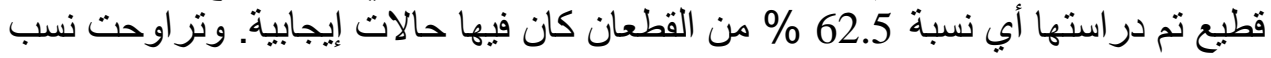
انتشار الحالات الايجابية في قطعان الدراسة بين (4 \% 82 (6) - 25 \% \%). سجلت أن الدراسة 8.61 \% (

للأجسام المضادة النوعية للكلاميديافيلا المجهضة و الانة الانتشار المصلي للكلاميديافيلا

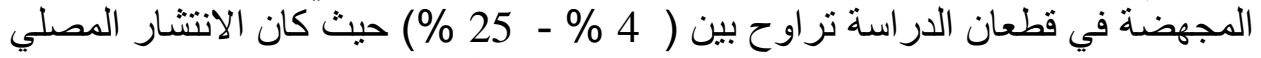

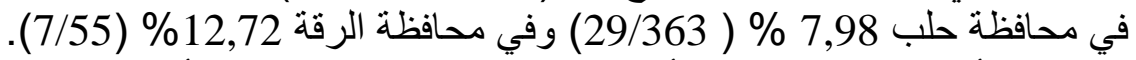

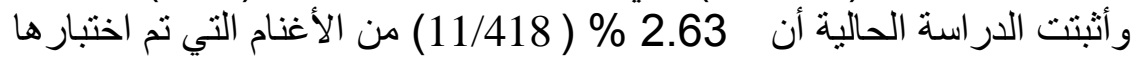

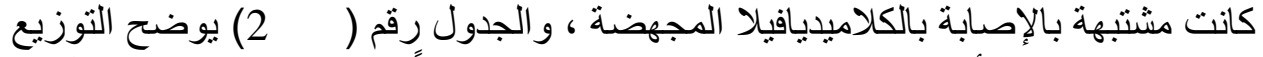

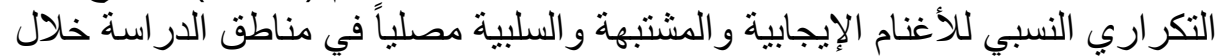
الفترة من تشرين الثاني لعام 2009 وحتى شهر نيسان لعام الإبـ 2010.

الجدول رقم 2: التوزيع التكراري النسبي للأغنام الإيجابية والمشتبهة و السلبية مصلياً في مناطق الدر اسة خلال الفترة من تشرين الثاني لعام

$$
\text { نيسان لعام } 2010 .
$$

\begin{tabular}{|c|c|c|c|}
\hline التوزيع التكر اري المئوي السلبية (\%) & للأغنام المشتبهة التيعر المئوي & معدلات الإجهاض & المحافظة \\
\hline $88.98(323 / 363)$ & $3.03(11 / 363)$ & $7.98(29 / 363)$ & حلب \\
\hline $87.27(48 / 55)$ & $0(0 / 55)$ & $12.72(7 / 55)$ & الرقة \\
\hline $88.75(371 / 418)$ & $2.63(11 / 418)$ & $8.61(36 / 418)$ & المجموع \\
\hline
\end{tabular}


وقد تبين من مقارنة نتائج الاختبار المصلي مع أعمار أغنام الدراسة أن 12

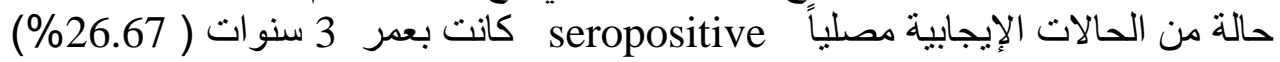

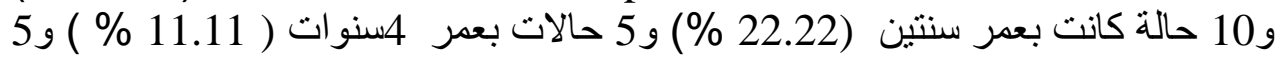

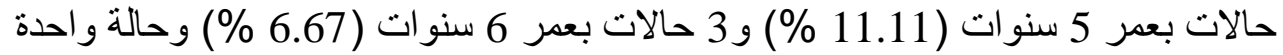

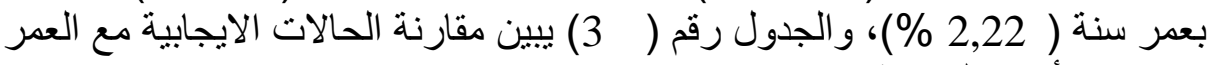
الإنتاجي لأغنام الدراسة.

الجدول رقم 3: مقارنة الحالات الايجابية مع العمر الإنتاجي لأغنام الدراسة في المنطقة الثمالية من سورية.

\begin{tabular}{|c|c|c|c|c|}
\hline المئوزي للحيو التكر ارتي & المئوي للحييو النارت الإيجية & التكرار المطلق & اللتكيو النات المطلق & الحيوان/سنة \\
\hline 0 & 2.22 & 0 & 1 & 1 \\
\hline 6.67 & 22.22 & 3 & 10 & 2 \\
\hline 6.67 & 26.67 & 3 & 12 & 3 \\
\hline 8.89 & 11.11 & 4 & 5 & 4 \\
\hline 2.22 & 11.11 & 1 & 5 & 5 \\
\hline 0 & 6.67 & 0 & 3 & 6 \\
\hline
\end{tabular}

وباستخدام اختبار بيرسون مربع كاي

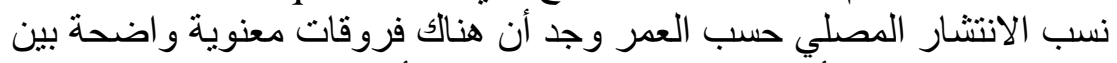

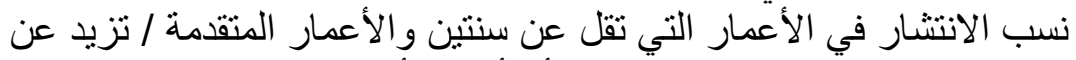

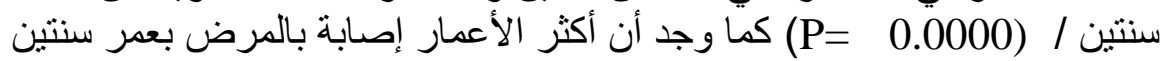

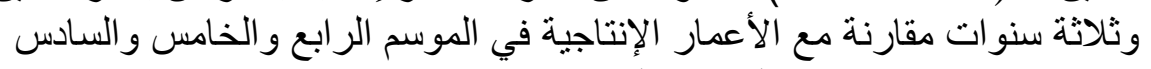
الإنتاجي و بفروقات معنوية واضئ واضحة (P=0.0000).

التحليل الإحصائي: Statistical Analysis Methods

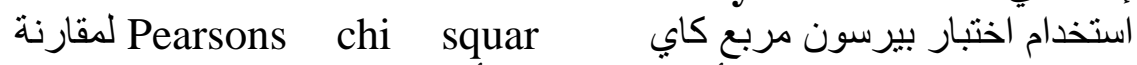

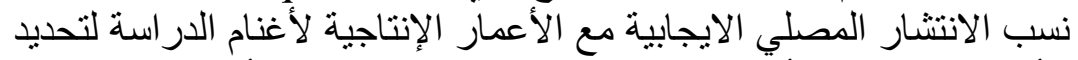

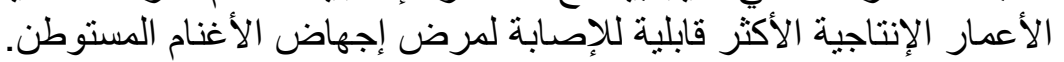

\section{DISCUSSION and CONCLUSION المناقشة والاستنتاجات}

تعد أمر اض الإجهاض هي من الأمر اض المستوطنة في الجمهورية العربية

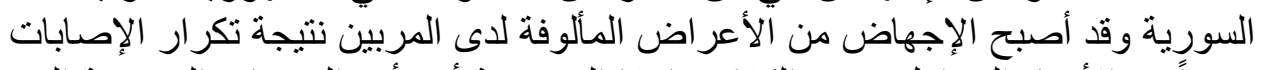

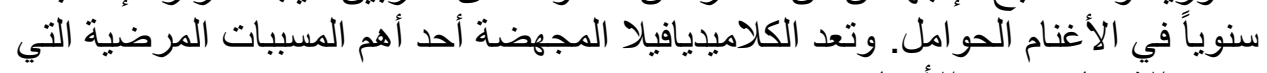
تسبب الإجهاض عند الأغنام) (OIE, 2000 ; Da Silva et al., 2006).

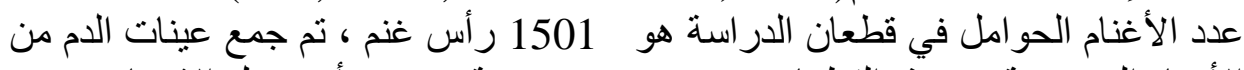
الأغنام المجهضة في هذه القطعان و عدده 418 عينة. وتبين بأن معدل الإجهاض هو هو 
27.85 (418/1501) كما هو موضح في الجدول رقم (Aikten, 1993). و الأجسام

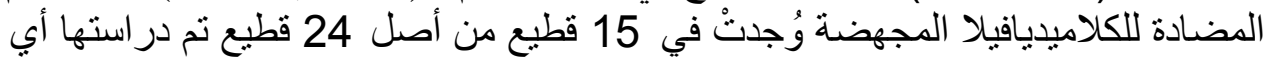

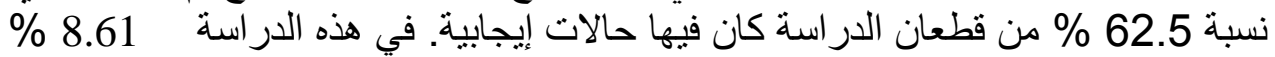

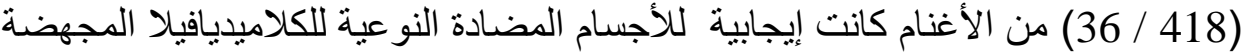

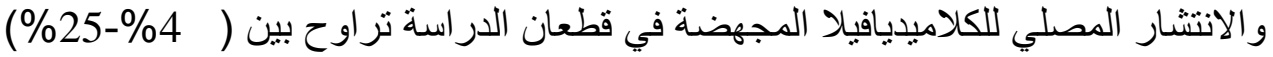

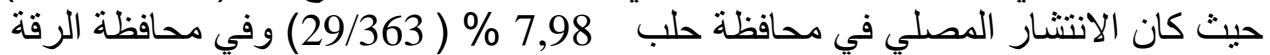

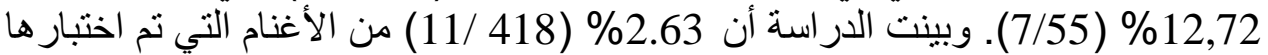

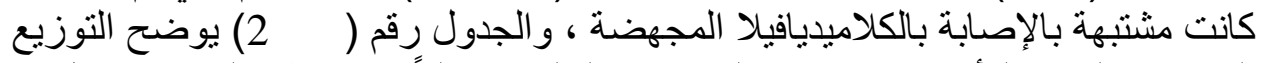

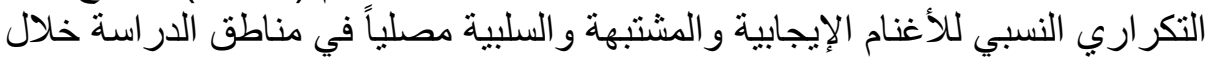

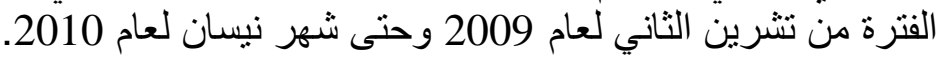

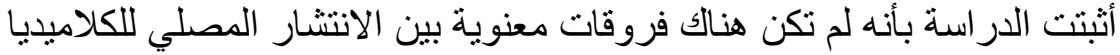

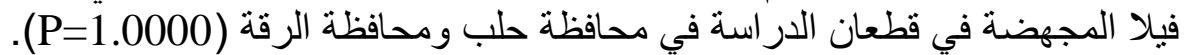
وسجلت الدراسة أن أعلى انتتار مصلي الإنابي في الأعمار الإنتاجية المتر اوحة الإنة

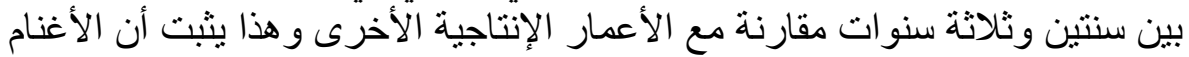

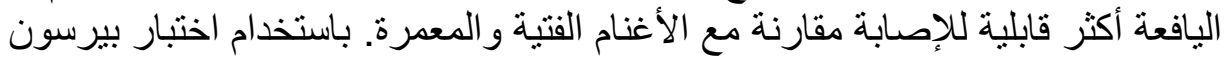

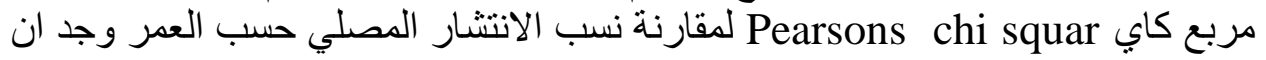

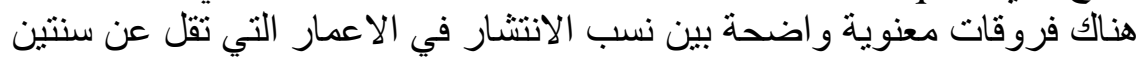

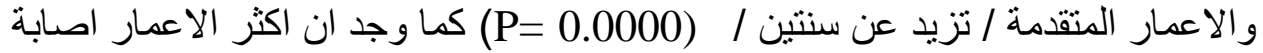

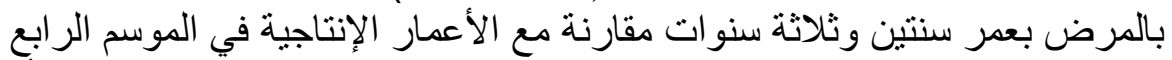

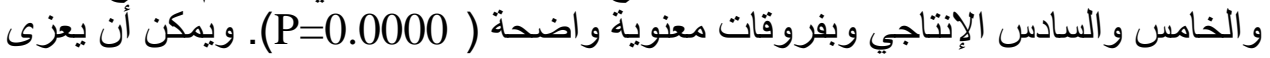

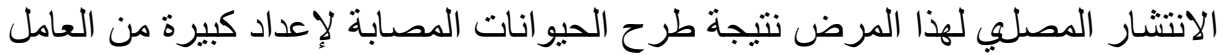

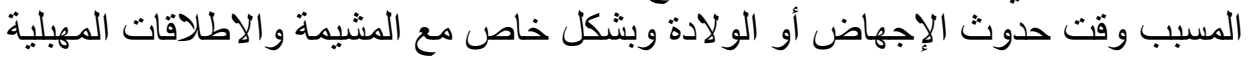

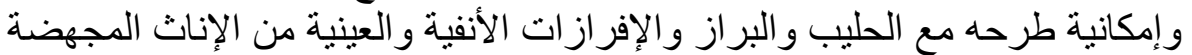

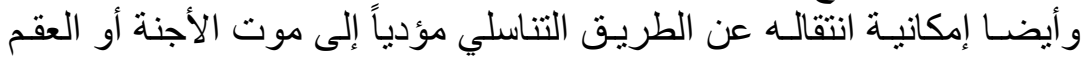
(Nietfeld, 2001 ; Masala et al., 2005 ; Da Silva et al., 2006)

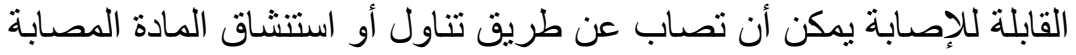

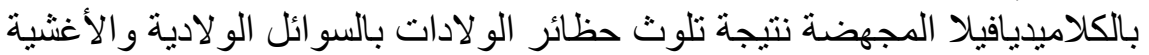

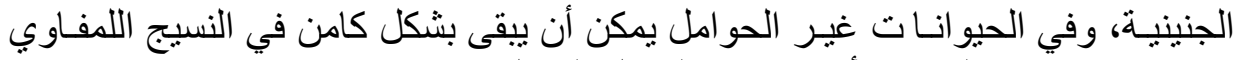

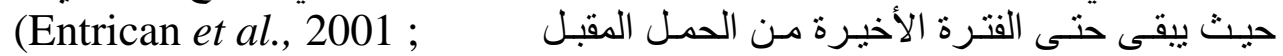
ويمكن أن يستمر طرح العامل المسبب Nietfeld, 2001 ; Da Silva et al., 2006) خلال دورات الثبق والو لادات اللاحقة ولهذا يستمر تلوث البيئة وانتشار العدوى الني .(Nietfeld, 2001 ; Da Silva et al., 2006) الانتشار المصلي للحالات الايجابية الذي سجلته هذه الدراسة يتو التو افت بشكل تقريبي

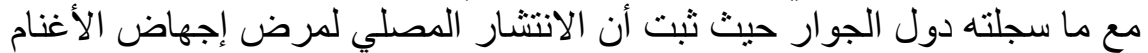

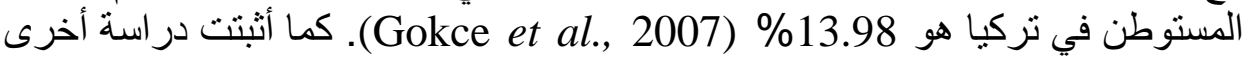

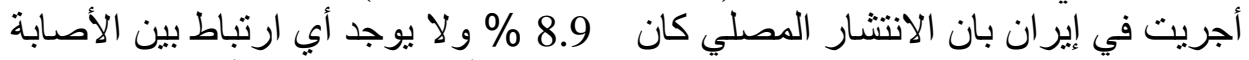
و العمر الانتاجي (Ghorbanpoor et al., 2007). أما في المملكة الأردنية فمن خلان الإن 


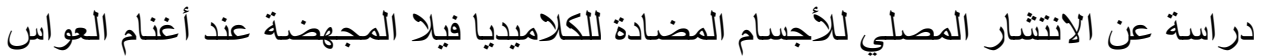

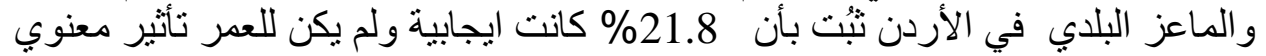

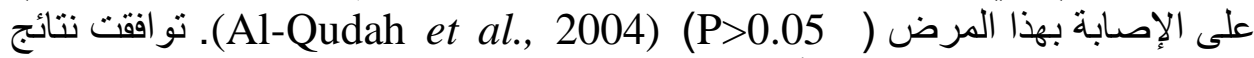

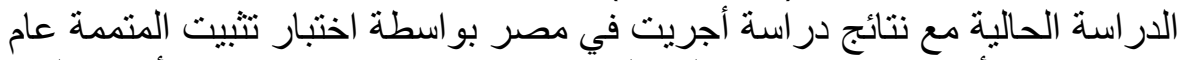

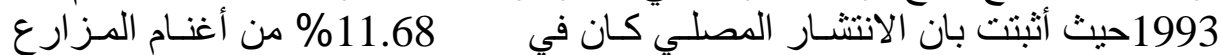

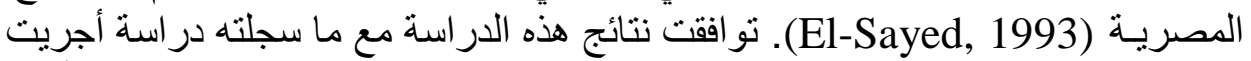

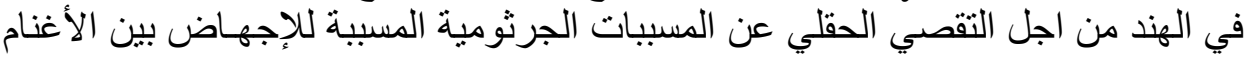

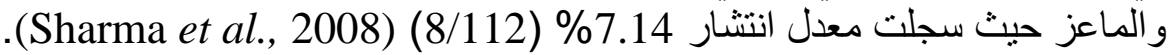

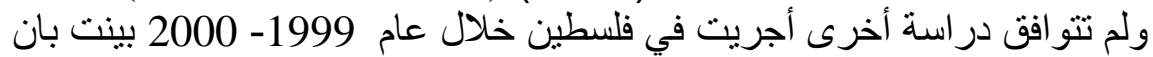

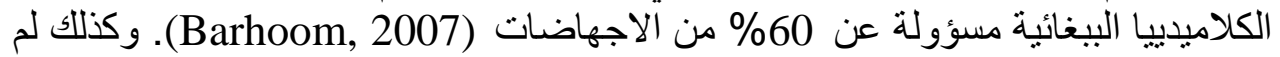

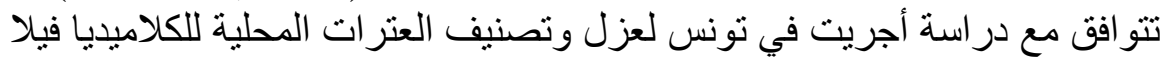

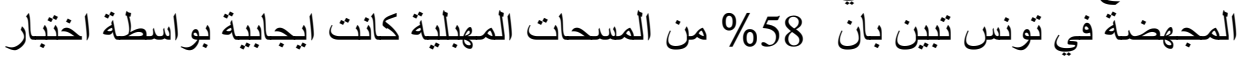

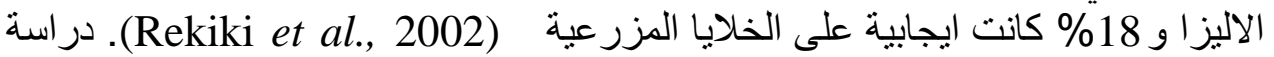
أخرى أجريت في البرازيل لتحديد الانتشار المصلي للكلاميديا فيلا المجهضة في البرائ البرازيل

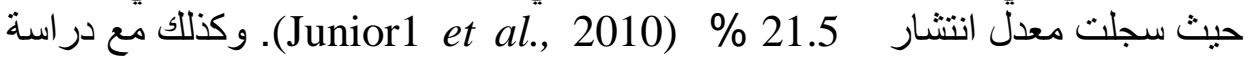

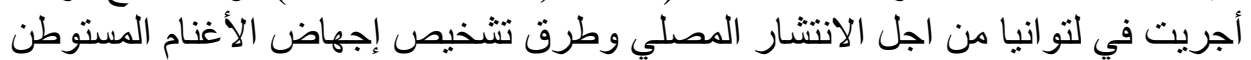

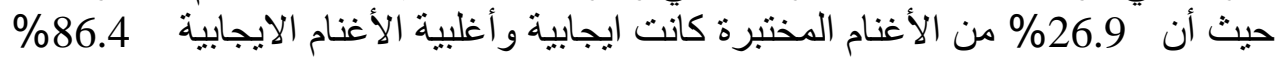

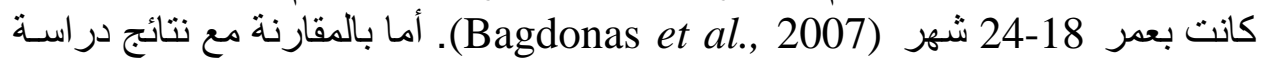
أجريت في جزيـرة سردينيـا في ايطاليا فقد كانت نتائج الدر اسة اقل مما سجلتهـ نتائسج

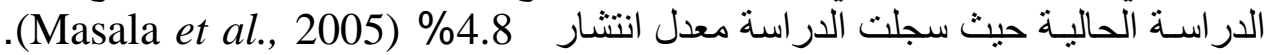

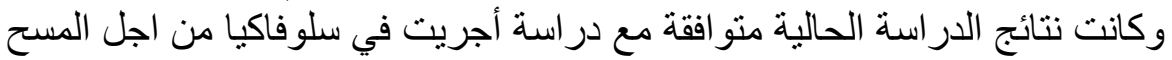

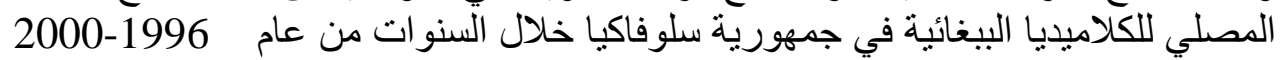

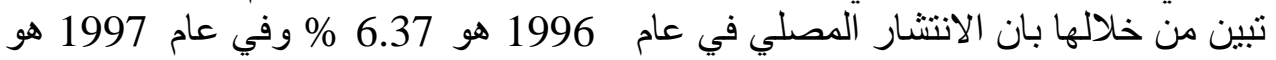

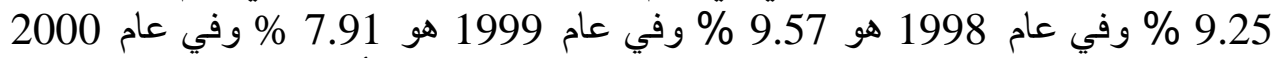

هو 10.99 \% (Travnieek et al., 2001). تشير النتائج بأن عدوى الكلاميديافيلا

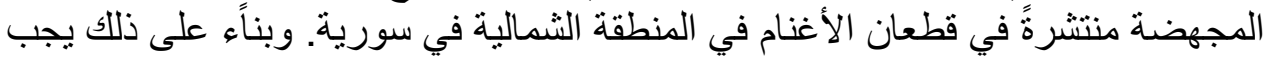

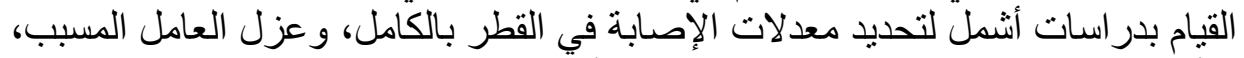

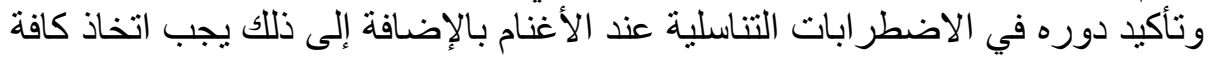

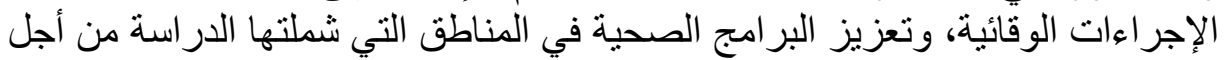

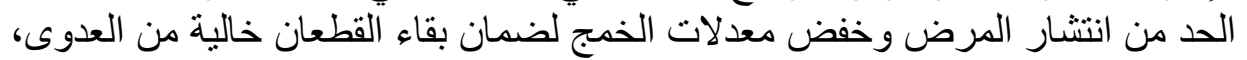
ولخفض تلوث البيئة بهذه المسببات وخطر انتقالها المحتمل إلى الإنسان.

\section{REFERENCES}

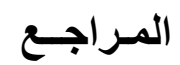

Aikten, I.D. (1993): Ovine clamydial abortion. In: Woldehiwet, Z.; Ristic, M. (Eds.), Rickettsial and Chlamydial. Diseases of Domestic Animals. Pergamon Press: Oxford, p. 349-360. 
Aikten, I.D. (2007): Clamydial abortion. In: Aikten, I.D. Diseases of Sheep. Blackell Science: Oxford, p. 247-290.

Al-Qudah, K.M.; Sharif, L.A.; Raouf, R.Y.; Hailat, N.Q. and Al-Domy, F.M. (2004): Seroprevalence of antibodies to Chlamydophila abortus shown in Awassi sheep and local goats in Jordan. Vet. Med. - Czech, 12: 460-466.

Appleyard, W.T.; Aitken, I.D. and Anderson, I.E. (1985): Attempted veneral transmission of Chlamydia psittaci in sheep. Vet. Rec. 116: 535-538.

Bagdonas, J.; Šalomskas, A.; Petkevičius, S.; Augustinavičius, Ž.; Gerulis, G. and Mockeliūnas, R. (2007): The Prevalence and diagnostic methods of ewes enzootic abortion in Lituania. Vetrinarijair Zootechnik. T. 37 (59).

Barhoom, S. (2007): Enzootic abortion of ewes (ovine chlamydiosis): diagnosis and control. The Islamic University J., 15( 2): 15-19.

Borel, N.; Doherr, M.G.; Vretou, E.; Psarrou, E.; Thoma, R. and Pospischil, A. (2004): Seroprevalences for ovine enzootic abortion in Switzerland. Prev. Vet. Med. 2004, 65: 205-216.

CFSPH "The Center for Food Security and Public Health. Zoonotic Clamydiae from Mammals" (2009): Available at: http://www.cfsph.iastate.edu. Accessed: 01 february 2008.

Da Silva, F.G.; De Freitas, J.C. and Muller, E.E. (2006): Chlamydophila abortus in production animals. Cienc Rural, 36: 342-348.

El-Sayed, A.S.A. (1993): Studies on chlamydiosis in farm animals. $\mathrm{Ph}$. Thesis (Infectious diseases). Fac. Vet. Med., Cairo Univ., Egypt

Entrican, G.; Buxton, D. and Longbottom, D. (2001): Chlamydial infection in sheep: immune control versus fetal pathology. J. Roy. Soc. Med. 94: 273-277.

Entrican, G. (2002): Immune regulation during pregnancy and hostpathogen interactions in infectious abortion. J. Comp. Pathol., 126: 79-94.

Everett, K.D.E.; Bush, R.M. and Andersen, A.A. (1999): Emended description of the order Chlamydiales, proposal of Parachlamydiaceae fam. nov. and Simkaniaceae fam. nov., each containing one monotypic genus of the family Chlamydiaceae, including a new genus and five new species, and standards for the identification of organisms. Int. J. System. Bact., 49: 415-440.

Galiero, G. (2007): Causes of infectious abortion in the Mediterranean buffalo. Ital. J. Anim. Sci. 6: 194-199. 
Ghorbanpoor, M.; Goraninejad, S. and Heydari, R. (2007): Serology study on enzootic abortion of ewes in Ahvaz, Iran. Journal of Animal and Veterinary Advances 6(10): 1194-1196.

Gokce, I.H.; Kacar, C.; Genc, O. and Sozmen, M. (2007): Seropevalance of chlamydophila abortus in aborting ewes and dairy cattle in the north-east part of turkey, Bull Vet Inst Pulawy, 51: 9-13.

Jones, G.E. and Anderson, I.E. (1988): Chlamydia psittaci: Is tonsilar tissue the portal of entry in ovine enzootic abortion. Res. Vet. Sci., 44: 260-261.

Jorgensen, D.M. (1997): Gestational psittacosis in a Montana sheep rancher. Emerg. Infect. Dis., 3: 191-194.

Junior1, J.; Mota, A.; Piatti, M.; Oliveira, F.; Silva, A.; Abreu, S.; Anderlini, G.; and Valença, R. (2010): Seroprevalence of antibodies to chlamydophila abortus in ovine in the state of ALAgoas, Brazil. Brazilian Journal of Microbiology, 41: 358-364.

Longbottom, D.; Fairley, S.; Chapman, S.; Psarrou, E.; Vretou, E. and Livingtsone (2002): Serological diagnosis of ovine enzootic abortion by enzyme-linked immunosorbent assay with a recombinant protein fragment of the polymorphic outer membrane protein POMP90 of Chlamydophila abortus. Journal of Clinical Microbiology, 40: 4235-4243.

Masala, G.; Porcu, R.; Sana, G.; Tanda, A. and Tola, S. (2005): Role of Chlamydophila abortus in ovine and caprine abortion in Sardinia, Italy. Vet. Res. Commun. 29: 117-123.

Morgan, K.L.; Wills, J.M. and Howard, P. (1988): Isolation of Chlamydia psittaci from the genital tract of lambs: A possible links with enzootic abortion in ewes. Vet. Rec.123: 399-400

Mousa, H.A.A.; Mahmoud, H.A. and Ibrhim, M.A. (2010): Detetion of Chlamydia in rabbit using traditional methods and electron microscope. Global Veterinaria 4(1): 74-77.

Niemczuk, K. (2005): Prevalence of antibodies against Chlamydia psittaci and Chlamydophila abortus in cattle in Poland. A preliminary report. Bull Vet Inst Pulawy, 49: 293-297.

Nietfeld, J.C. (2001): Chlamydial infections in small ruminants. Vet. Clin North Am Food Anim Pract, 17: 301-314.

OIE "Office International De Epizooties" (2000): Manual of Standard Diagnostic Tests and Vaccines

OIE "Terrestrial Manual" (2008): Office International des Epizooties. Chapter 2.7.7. -Enzootic abortion of ewes (ovine chlamydiosis). 
In: Manual of diagnostic testes and vaccines for terrestrial animals (mammals, birds and bees) 4th edn. World organisation for animal health, pp. 1013-1020.

Papp, J.R.; Shewen, P.E. and Gartly, C.J. (1994): Abortion and subsequent excretion of chlamydiae from the reproductive tract of sheep during oestrus. Infect. Immun., 62: 3786-3792.

Rekiki, A.; Sidi-Boumedine, K.; Souriau, A.; Jemli, J.; Hammami, S. and Rodolakis, A. (2002) Isolation and characterization of local strains of Chlamydophila abortus (Chlamydia psittaci serotype 1) from Tunisia. Vet. Res., 33: 215-222.

Rodolakis, A.; Salinas, J. and Papp, J. (1998): Recent advances on ovine chlamydial abortion. Vet. Res. 29 (3/4): 275-288.

Sharma, M.; Batta, K.M.; Katoch, R.C. and Andersen, A.A. (2008): A field investigation of bacterial etiology of abortions among migratory sheep and goats in North-West hill states of India, Veterinarski Arhiv 78 (1), 65-71.

Shewen, P.E. (1980): Chlamydial infection in animals: a review. Can. Vet. J. 21: 2-11.

Travnicek, M.; Kovacova, D.; Bhide, M.R.; Zubricky, P. and Cislakova, L. (2002): Field evaluation of an iELISA and CF test for detection of IgG antibodies against Chlamydophila abortus in goats, sheep, and rams. Vet. Med. Czech, 47: 195-198.

Travnieek, M.; Kovaeova, D.; Zubricky, P. and Ėislakova, L. (2001): Serosurvey of sheep and goats to Chlamydia psittaci in Slovakia during the years (1996-2000). Vet. Med. - Czech, 46: 281-285.

Vlahović, K.; Dovč, A. and Lasta, P. (2006): Zoonotic aspects of animal chlamydioses-a review. Veterinarski Arhiv 76 (Suppl.), S259-S274.

Vretou, E.; Radouani, F.; Psarrou, E.; Kritikos, I.; Xylouri, E. and Mangana, O. (2007): Evaluation of two commercial assays for the detection of Chlamydophila abortus antibodies. Veterinary Microbiology, 123: 153-161.

Williams, E.J. and Donovan, J.O. (2009): Ovine abortion: an overview, Irish Veterinary Journal 62, 5: 342-346.

Wilsmore, A.J.; Dawson, M.; Trower, C.J.; Venables, C. and Arthur, M.J. (1986): Ovine enzootic abortion: field observations on naturally acquired and vaccine-elicited delayed type hypersensitivity to Chlamydia psittaci. Vet. Rec., 118: 331-332.

Wilsmore, A.J. and Dawson, M. (1990): Chlamidial diseases of ruminant in Britain. In: Aitken, D. Agriculture Chlamydial diseases of 
Assiut Vet. Med. J. Vol. 57 No. 128 January 2011

ruminants. Commission of the European Communities Seminar, p.13-16 